\section{The Multiple Tensions of Organizational Hybridism: A Look at the Translation Perspective and Open Strategy in a Social Enterprise}

\author{
Eduardo Guedes Villar' \\ Natália Rese ${ }^{1}$ \\ Karina De Déa Roglio' \\ ${ }^{1}$ Federal University of Paraná, School of Management, Curitiba, Brazil
}

Received on 10/31/2018

Approved on

04/03/2019

Responsible editor:

João Maurício Gama

Boaventura

Evaluation process:

Double Blind Review

\begin{abstract}
Purpose - In this research we seek to understand how a social enterprise deals with the multiple tensions of organizational hybridism to achieve its strategic objectives.

Design/methodology/approach - A qualitative single-case study was performed using longitudinal and in-depth data collection. For the analysis and interpretation of the data an abductive logic and narrative analysis were used.
\end{abstract}

Findings - We concluded that the actors were involved in various openness practices for inclusion, transparency, flexibility, and horizontalization in the strategic process. We also found evidence that the practices of opening up the strategy support a translation process, thus minimizing the tensions of organizational hybridism. This translation process was redefined in the context of hybridism.

Originality/value - This research showed that actor-network theory, in particular the translation perspective, is indicated for the study of social enterprises. Concerning the process of opening up the strategy, it is suggested that the process of horizontalizing relationships and flexibility is necessary in the strategic process, in addition to inclusion and transparency. Another contribution is related to the translation process in hybrid organizations, suggesting a reduction of the political imposition of roles and identities.

Keywords - Organizational hybridism; Social enterprise; Translation; Open strategy; Actor-network theory.

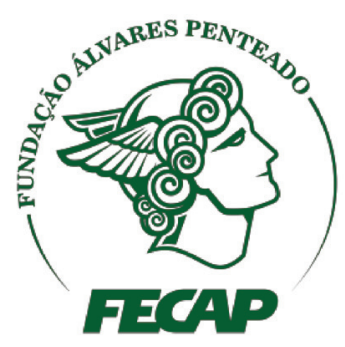

Review of Business Management

DOI: $10.7819 /$ rbgn.v21i3.4001 


\section{Introduction}

Organizational boundaries have become blurred, and this alteration has been epitomized by the emergence of hybrid organizations, which are characterized by (i) combining aspects of multiple organizational formats (Hoffman, Badiane, \& Haigh, 2012), (ii) deviating from sociallylegitimated organizations and, as a result, (iii) they face challenges in terms of organizing (Battilana \& Lee, 2014). Doherty, Haugh, and Lyon (2014) define hybrid organizational forms as structures and practices that permit the coexistence of values and artifacts from two or more categories, for example the economic and social categories. In this sense, social enterprises present a new and intriguing empirical investigation context (Dacin, Dacin, \& Tracey, 2011) for understanding organizational hybridism (Battilana and Lee, 2014).

Many studies focus on internal tensions generated by organizational hybridism, such as problems related to the identity of organizational members and the distribution and allocation of resources (Battilana \& Dorado, 2010). However, studying the formation and interaction of the external relationships of a social enterprise (Battilana \& Lee, 2014) and how they are reconciled with the sometimes conflicting multiple agendas of various actors within these networks (Bridgstock, Lettice, Özbilgin, \& Tatli, 2010) presents a research opportunity in this area.

Thus, this theoretical-empirical study seeks to analyze the organizational mechanisms adopted by a social enterprise to deal with the tensions that result from hybrid organizations. We will use the concept of open strategy to analyze the phenomenon in question (Whittington, Cailluet, \& Yakis-Douglas, 2011; Dobusch \& MüllerSeitz, 2014) as well as the translation perspective presented by actor-network theory (Callon, 1986; Latour, 2005). The concept of an open strategy is interesting due to the process of inclusion and communication with stakeholders, which can be an alternative strategy to deal with the external tensions of a social enterprise (Rese, Salvador, \& Araújo, 2016).

To complement this, the translation perspective consists of an analytical structure to study how power relationships are structured (Callon, 1986). This is a negotiation process in which meanings, complaints, and interests change and gain space (Wæraas \& Nielsen, 2016). Doherty et al. (2014) suggest that hybrid organizations are by definition places of conflict, contradiction, and contestation. Thus, translation theory presents theoretical adherence to studying how hybrid organizations change given the complexity and disorder that characterize them (Battilana \& Lee, 2014).

The justification for studying social enterprises is based on these main characteristics: (i) organizational hybridism, which requires greater understanding and new theorization (Battilana, Besharov, \& Mitzinneck, 2017); (ii) the representation of an extreme case of hybridization, which offers a distinctive framing for studying hybrid organizations (Battilana \& Lee, 2014); (iii) the opportunity to question the basic assumptions regarding the unified nature of an organization's forms and objectives (Battilana \& Lee, 2014); and (iv) their tendency to present conflict and instability (Besharov \& Smith, 2014), which provides a "ready-made laboratory to study a creative variety of the hybrid type" (Billis, 2010, p.13). Battilana et al. (2017) argue that understanding the effective performance of hybrid organizations requires one to consider the interaction of challenges, opportunities, and various strategies. Smith, Gonin, and Besharov (2013) suggest that future work should consider other potentially useful approaches to understanding the tensions experienced by social enterprises. And, in addition, the open strategy and the sociology of translation approach can help develop new insights (Dacin et al., 2011; Guimarães \& Alves, 2014) to enrich the theory in this area, offering potential responses to the issues presented by the authors cited. 


\section{Theoretical foundations}

This section examines the theoreticalconceptual body of work that this study is based on. It presents the concepts of hybrid organizations and social enterprises, and the main theoretical articulations made in related studies. Next, we will examine the concept of open strategy and its characteristics. Finally, we will present a review of the literature on translation theory.

\section{I Hybrid organizations and social enterprises}

the term hybrid is used in a variety of ways in the organizational literature. Battilana et al. (2017) identify three groups with distinct perspectives in the way in which they treat the hybrid concept: hybrid organizational identities, hybrid forms, and hybrid rationality. In this paper, we will discuss hybridism in terms of institutional logic: "Based on the perspective of institutional logic, hybrid organizations are those that are based on values and norms using various forms of logic within distinct fields - or social levels" (Battilana et al., 2017, p. 137). The perspective of institutional logic within organizational institutionalism emphasizes organizational pluralism and differentiation as responses to institutional pressures, challenging traditional isomorphic responses (Ocasio, Thornton, \& Lounsbury, 2017). In this sense, the idea that an organization can be submitted to different forms of institutional logic, and that therefore its pressures can be varied and even conflicting, opens up space for a discussion of human agency in relation to organizational institutionalism (Friedland \& Alford, 1991). Hybridism, within this discussion, arises as one of the consequences of organizational practices in organizations that are subject to a variety of potentially conflicting forms of institutional logic (Ocasio et al., 2017; Battilana et al., 2017).

To study hybrid organizations, Battilana and Lee (2014) indicate that social enterprises are ideal types of this phenomenon (understood as methodological resources cited by the authors). Social enterprises pursue the double mission of achieving financial sustainability and social purpose and, therefore, they do not fit perfectly into conventional categories of private, public, or non-profit organizations (Doherty et al., 2014). Hoffman et al. (2012) suggest that traditional organizational models are not designed to deal with the tensions that result from hybrid rationalities, such as organizations that need to meet environmental and social demands as well as demands in terms of efficiency. Thus, the authors suggest that models for social enterprises are based on an expectation of institutional change, organizational (re)structuring, and social-economic mobilization, which are capable of reconfiguring the way in which the contexts of hybrid rationalities are developed. Even though Battilana and Lee (2014) believe that social enterprises typify hybrid organizations, Battilana et al. (2017) discusses the phenomenon of hybridism as a question of degree, much more than a configuration of a different type of organization: in this sense, it is understood that organizations in general present some degree of hybridism.

Based on this discussion, we can observe that organizations vary to the extent that they confront multiple forms of institutional logic, the extent that these multiple forms are contradictory, and the extent to which one or another logic is central to the performance of these organizations (Besharov \& Smith, 2014; Battilana et al., 2017). It becomes relevant, therefore, to analyze how hybrid organizations deal with the various types of tension caused by this hybrid nature based on their managerial practices, as proposed in this paper.

Social enterprises are treated in this study in a way that goes beyond the ideal typification proposed by Battilana and Lee (2014). They configure them as a subject of research, which due to their hybrid characteristics defy institutional concepts of "doing business." The assumption that supports this affirmation is that models, tools, and 
the forms of organization that are appropriate for productive or public organizations (which already have a vast body of work in terms of academic studies and managerial production) are not appropriate for organizations that have a great degree of hybridism, such as social enterprises. In presenting a large degree of hybridism, they can reveal elements that are relevant to the organizing ${ }^{l}$ movement, which occurs in a live form. In these cases, the taken-for-granted dimension of organizing is less evident, which makes it possible for the researcher to examine the various dimensions of organizing in a more engaged manner.

Social enterprises seek to carry out social innovations with the objective of developing and implementing new ideas (products, services, and models) to meet social needs (Bridgstock et al., 2010). Doherty et al. (2014) note that social enterprises tend to be a coalition of multiple interest groups, which all have their own priorities that are often divergent. The strategy development process for a social enterprise involves the time and resources dedicated to the creation of networks, communication, lobbying, and negotiation with the interested parties to achieve a consensus on key issues (Doherty et al., 2014). This negotiation process between organizations is necessary to avoid the enterprise's failure, to construct and maintain legitimacy, and to mobilize the financial resources needed for its activities.

\subsection{Open strategy}

The purpose of an open strategy is based on the development of strategic studies as social practice (e.g. Tureta \& Lima, 2011; Vaara \& Whittington, 2012). This new look at strategy is far from uniform or complete, because it involves a group of practices within a variety of contexts (Whittington et al., 2011). For the authors, when comparing it to the phenomenon of open innovation, the open strategy process does not generate invariably positive results for organizations. It is evident that this openness can bring with it elements that are undesirable for the organization, and are not by definition synonymous with security (Dobusch \& MüllerSeitz, 2014.).

In the classic view, the formulation of strategy is exclusive, or in other words, it is the work of those who are responsible, namely the main executive or a small group of managers, the top management team (Hambrick, Finkelstein, \& Canella Jr., 2009). In addition, from this perspective, strategy is seen as an organization's secret resource (Mintzberg, 1987). As a result, Whittington et al. (2011) identify opening up strategy as a process of inclusion which encompasses actors external to the organization, as well as other internal actors who are not positioned at the top of the hierarchical organization.

The theoretical concept of open strategy is based on two particular dimensions of strategy making: opening it up in terms of inclusion and in terms of transparency (Whittington et al., 2011; Hautz, Seidl, \& Whittington, 2017). Inclusion refers to the incorporation of individuals into a strategic conversation (Mantere \& Vaara, 2008), or in other words, expanding it to exchange information, points of view, and proposals with other organizational levels and stakeholders who shape the continuous evolution of organizational strategies.

In the internal inclusion process, strategy is formed in a participative manner, or in other words, individuals outside the top management team participate in the strategic process (Dobusch, Seidl, \& Werle, 2014). In the external inclusion process, consultants participate in the planning and implementation of organizational strategies (Ghemawat, 2002) and workshops are held with organizations from the same sector (Whittington et al., 2014) to explore opportunities and strategic threats together. Dobusch (2012) identifies organizational openness to external contributions in which strategy can be carried out in a collaborative manner through a crowdsourcing process.

Transparency, in turn, refers to the visibility given to an organization's strategic 
information, possibly during the formulation process, but especially in the diffusion of established strategies (Whittington et al., 2011). Internal transparency is necessary so that managers understand organizational strategies instead of simply implementing or executing them. Technology and information system tools are employed to make transparency possible.

Having an open strategy process increases difficulties with or the possibility of having confidential strategies, given that the first to move and the imitators gradually draw closer (Whittington et al., 2011). Advanced technologies, the ease of access to information, and the increase in social interactions through online tools make transparency an almost inevitable phenomenon. Thus, even though the process of open strategy is far from complete, it has led to the appearance of new organizational models and has changed managerial cultures that were previously based on opaqueness and elitism (Whittington et al., 2014).

It should also be noted that an organization's decision to be open is dynamic: first because it permits the existence of different combinations of transparency and inclusion to promote openness, and second because openness can vary over time and according to organizational needs and objectives. Hautz et al. (2017) propose the understanding that the dynamics between these two dimensions (transparency and inclusion) is represented as a continuum, which permits different movements and configures the possibilities of opening up organizational strategy.

\subsection{The translation perspective}

from this perspective, it is understood that reality does not have a stable and definitive status composed of heterogeneous material networks (human and non-human) that are united (Latour, 2005; Tureta, Tonelli, \& Alcadipani, 2011). In the actor-network theory (ANT) approach, the word translation takes on the particular meaning of "a relationship that does not transport causality, but induces two mediators to exist" (Latour, 2005, p. 108). Translation makes it possible to reach a simple but also fundamental explanation of how some manage to have the right to express themselves and represent many silent actors in the social and natural worlds that they mobilize (Callon, 1986; Camillis, Bussular, \& Antonello, 2016).

To trace the construction of a relationship network, the phenomenon of translation occurs at four moments: (i) questioning; (ii) interessement; (iii) enrollment $t^{2}$; and (iv) mobilization. Questioning, the first moment of translation (Callon, 1986), consists of the determination of a group of roles and their respective identities to establish a common form of passage in the relationship network that it intends to construct. This moment involves the determination of roles and identities and is also called framing (Callon, 1998). According to Callon (1986), at the moment of questioning, one of the actors (the protagonist) seeks to become indispensable. The framework of established relationships delineates which interactions occur in a manner that is more or less independent of the surrounding context (Callon, 1998). The author shows that the importance and content determined at the moment of questioning are evident to the protagonists, or in other words, those who wish to become politically indispensable within the relationship network. In addition, questioning has certain dynamic properties in which movements and deviations can be accepted and alliances should be forged (Callon, 1986).

At the interessement moment, identities have already been formed, but the relationships foreseen at the moment of questioning still have not been tested (Callon, 1986). Thus, it seeks to establish the links between the "interests" of various actors (Wæraas \& Nielsen, 2016). The identity and the geometry of the "interested" entities are modified during the entire interessement process (Callon, 1986). Or in other words, they are formed and adjusted only during action. Interessement is based on the interpretation of who the actors are, and also an understanding 
of which entities these actors are (or need to be) associated with (Callon, 1986).

In terms of the enrollment moment, Callon (1986) affirms that it designs the device through which a series of interrelated roles are defined and attributed to the actors who accept them. In other words, interessement reaches enrollment if the process is successful. In the enrollment process, the definition and distribution of roles are the result of multilateral negotiations, in which the identities of the actors are determined and tested. Enrollment involves the acceptance of roles in the prioritization within a given framing (Wæraas \& Nielsen, 2016).

The fourth moment of translation is termed mobilization by Callon (1986) and consists of maintaining the network, assuring that the spokesperson acts in accordance with its interests (Wæraas \& Nielsen, 2016). For Callon (1986), social and natural realities are the results of negotiations about the representativeness of spokespeople. And during translation continuous interessement adjustments and devices may be necessary.

Translation involves these processes, not necessarily in a defined order, but in ways that seek "to create convergences and homologies relating things that were different before" (Callon, 1980, p. 221). For Latour (1986), they do not necessarily end up being convergences or homologies, but rather a process of continuous transformation, which always results in a chain of unique translations.

In light of these three perspectives and their shared understanding that organizing is complex and contextual and defies normativeprescriptive models, we would like to present this study's theoretical argument. Given these new organizational dynamics, of which social enterprises are emblematic examples (Battilana \& Lee, 2014), the institutionalized explanatory models of organizational practices appear to be incomplete (Battilana et al., 2017). It is understood that organizations tend toward hybridism to different degrees (Besharov \&
Smith, 2014). Organizations such as social enterprises, which represent the radicalization of hybridism and need to deal with contradictory forms of institutional logic, have been discussed theoretically, but there have been few empirical studies that address the implications of hybridism in relation to performance and organizational practices (Battilana et al., 2017). Hence, the perspective of open strategy (Hautz et al., 2017), which understands that the strategic process involves increments in transparency and the inclusion of strategic issues as organizations have a need for constant innovation and deal with contradictory aspects, presents a path for dealing with the performance implications and organizational practices that hybridism may entail. It is understood, however, that the ontology of social relationships based on these two theoretical points of view needs a reassignment of meaning. A relational ontology (Callon, 1986; Latour, 2005), which seeks to understand social phenomena based on a relationshiplevel analysis (Wæraas \& Nielsen, 2016) of the combinations of different degrees of hybridism, and open strategy approaches instead of stable entities would seem to complete the explanatory framework of this article's theoretical argument. The concept of translation (Wæraas \& Nielsen, 2016) appears to be an "amalgam" that brings organizational social phenomena close to the level of action, and therefore explains organizational mechanisms adopted by social enterprises to deal with the tensions that result from having a hybrid organization.

\section{Methodological procedures}

To achieve this study's objective, we performed an instrumental case study of "Empresa Solidária" (ES), or "Solidarity Company" (a fictitious name), which has been in operation for more than 8 years as a social enterprise. An instrumental case study is a study of a unique case in which the researcher seeks a better analytical understanding of the phenomenon or even its theorization (Stake, 2000). Since it is a social 
enterprise, it was chosen intentionally because it characterizes an "ideal type" of a hybrid organization (Battilana \& Lee, 2014).

As a justification for choosing this unique case, we would like to emphasize i) the existence of various forms of logic in ES's business model, ii) the need for transparency and inclusion as premises for its socially-engaged activities, and iii) the recognition of the organization's performance by national bodies. Thus, besides being a special locus in which an elevated degree of hybridism and transparency can reveal interesting data for empirical studies (of which few have been conducted in these fields), the chosen case has been recognized for its performance in the sphere of social enterprises: ES is the only organization that has won both of the major social entrepreneurship awards in Brazil. In 2013, ES received the Social Entrepreneur of the Future Award from the newspaper with the largest circulation in the country. In 2014, the social enterprise under examination was awarded the Inspiring Youths Award, which is the largest entrepreneurial award in Latin America and is organized by the largest editorial group in the country. In 2018, one of the co-founders of ES was included in the "Under 30" list of young talents of Brazil, which was published in the national edition of one of the largest business magazines in the world. This recognition makes the ES case unique and potentially interesting in terms of theorization (Stake, 2000).

\section{I Case description}

Empresa Solidária (ES), headquartered in the city of Curitiba in the state of Paraná, began its activities in 2008. At that time, the company's executive director, who had a sister with Down syndrome, proposed the creation of an enterprise designed to contribute to the management of institutions that meet the needs of handicapped people through consulting in the administration area. Institutions, according to the business methodology of Empresa Solidária, are every organization that provides support services to people with handicaps, including schools, institutes, NGOs, etc.

The organization's purpose consisted of providing administrative consulting services free of charge to other institutions, with these activities being supported by private social investment from partner companies. Private organizations that invest in ES's social projects are termed partners. This enterprise operates in four different fronts of action: (i) administrative consulting; (ii) corporate volunteer programs; (iii) diversity (awareness and inclusion of handicapped individuals in the workforce); and (iv) the development of social products.

In 2016, the company had 22 internal employees and received investment from 92 companies in the region of Curitiba, PR, besides various national and multinational firms. In that year, ES worked directly with 117 institutions that address the needs of handicapped individuals, mobilizing more than 2,900 volunteers and affecting 45,630 people (handicapped individuals, parents, and institution teachers). The company also operates in other cities in the state of Paraná (Maringá, São José dos Pinhais, and Araucária), in Santa Catarina (Joinville), and it recently opened a new office in São Paulo, SP.

\section{$3 \cdot 2$ Collection procedures}

This study was conducted between 2015 and 2017, and the data collection was divided into two phases. Between April 2015 and February 2016, seventeen interviews were conducted, twelve of which involved internal members of the organization (the board of directors, management, and assistants in the commercial and operations departments) and five with external members (partners, institutions, and members of the consulting board). The interviewees were selected using the snowball method, beginning with the executive director of ES and later through recommendations with other internal members and organization stakeholders. A total of 13 hours and 30 minutes of interviews were recorded 
and transcribed, which resulted in 205 pages of literal transcription. In addition, at the same time, 6 observations were made (in activities together with institutions, internal meetings, and consulting board meetings), which totaled 15 hours and 25 minutes spent in the field. After the observations, the researchers maintained a routine to prepare the field report to preserve the wealth of information and perceptions obtained through the observation process.

The second part of the research took place between the months of November 2016 and April 2017, in which the researchers broadened their routine of non-participant observation of the organization's activities. These observations took place during regular meetings with partners and the consulting board, some of them carried out through videoconferencing, which was necessary given the dispersed nature of ES's activities, in which members found themselves in different spaces (headquarters, partners, institutions) and used this technology to keep in touch. In these situations, the researchers and the subjects being researched (internal members, board members, institution, and/or partner representatives) participated in videoconference meetings. Given this characteristic of the organization under examination, the participation of the researcher in these events was important to more deeply understand the relationship matrix. In total there were 29 observation periods conducted over a period of 65 hours and 3 minutes. All of the observations were registered in a specific field diary, in accordance with the four groups of annotations indicated by Latour (2005). In addition, 608 pages of company documents were collected, including slide presentations, management reports, strategic planning, internal emails, and materials involving communication with stakeholders.

The quantity of data collected allowed the researchers to understand the organization's activities in depth, making it possible to analyze the information obtained and its theoretical articulation.

\subsection{Analytical procedures}

To analyze the data, we used the Atlas.ti v7 qualitative analysis program in order to organize the documental data, observation reports, and interview transcriptions, and to avoid being smothered by the volume of data. It is important to state that the organizational narratives were generally not presented as "readymade" literary narratives, with a clear sequence of events, actors, and facts in chronological order. The narratives "are discursive temporal constructions that provide a means for individual, organizational, and social sensemaking and sensegiving [...] [and] generally they are articulated only in fragments as part of organizational discourses" (Vaara, Sonenshein, \& Boje, 2016, p. 456). Understood in this manner, the field researcher has the fundamental task of organizing these fragments into a coherent narrative, capable of revealing the daily operations of organizational relationships. Thus, the use of Atlas.ti played the role of enabling the researcher, during field work as well as in handling the volume of data produced at each step of the research, to input this data into the software and organize it based on facts, events, actors, relationships, and time. As these aspects could be "codified," constructing an organizational narrative that makes it possible to understand their relational and chronological order, Atlas. ti provided support in the interpretation of this data. The data analysis was conducted in a nonlinear manner in two distinct and complementary phases.

The first phase, in line with the theoretical perspectives adopted by this study, is not based on pre-formatted analytical categories. In other words, the researchers sought to abductively understand the increasing interactions of multiple actors, giving special attention to the times and spaces in which these interactions could alter the course of action of the organization under examination. Given that organizational narratives are often only articulated in fragments of organizational discourse (Vaara et al., 2016, p. 456), abduction was a fundamental way to develop 
a comprehensive path to a relationship network between humans and non-humans in this case study. This abduction was only possible through ethnographic immersion in the field research that enabled the researcher to develop "current knowledge of the world [of this organization]" (Eco, 2015, p. 202), which was the basis for constructing the significant relationships of the fragmented narratives through abductive logic. It is important to note that describing this abductive process is a complex task, given that it is not a linear process, nor is it a process of knowledge by correspondence, which is why it is impossible to demonstrate it linearly just by presenting narrative excerpts that exemplify the data. It is a process of theoretical-empirical creation in which the domain of the facts in the current world (which is known only through deep immersion in the world of those who experience it), as well as the domain of the codes of meaning mentioned in the literature, make it possible for the researcher to find a theoretical explanation. The three types of abduction follow the analytical path of the fragmented narratives - and in following this path, as has been noted, Atlas.ti was of great help in the following aspects:

(1) Hyper-codified abduction: by inputting narrative fragments in Atlas.ti, the researcher was first able to use codes, symptoms, and indications (Eco, 2015) to begin to structure the meaning of what was being said and observed. For example, one of the initial points of the story of how ES was born and developed was the idea of creating an index that would be capable of helping the performance of third sector organizations, ES's target public. The Executive Director's statement (repeated by various actors who make up this study's relationship network) "We needed a tool to understand institutions better" begins to give us an understanding that the organization's activities are based on a relationship network in which non-humans - the IDEE tool in this case - play a fundamental role. Thus, Atlas.ti began to develop a codification based on the theoretical domain in relation to the research problem, which generated this first phase of abduction. This first aspect of abduction makes it possible to classify clues in regard to the definition of what we are dealing with (the narrative theme of this fragment), but this still does not allow us to explain why and how these aspects exist as they do. Therefore, if we are faced with a hyper-codified abduction in which the researcher attempts "to decide to produce an initial enunciation of what has been produced as the scope of mentioning states of the world within our experience, [this] once again, is a question of pragmatic convention" (Eco, 2015, p. 208), which during this phase enables us to know "nothing more than surprising disconnected facts" (Eco, 2015, p. 208).

(2) Hypo-codified abduction: based on the identification of various disconnected enunciations (characteristics of organizational narratives, like the one just mentioned), the researcher becomes engaged in seeking a "topic" (Eco, 2015) or a narrative theme capable of establishing a coherent relationship among the data (Eco, 2015). This "topic" will make it possible to leverage fragmented narratives to understand the whole of the phenomenon under analysis. But the choice of a "topic" is not an arbitrary choice made by the researcher, and here is where the need comes in for the researcher's field immersion and maturation over time in a study of this nature, which is designed to make it possible to not only describe the established relationship network but also to be an actor in these relationships. Thus, the ability of the researcher to put order into these disconnected narratives in a coherent and accurate manner also comes from experience in this field and the possibility of constructing during this time "analogous intertextual frames", which in turn make it possible to perform hypo-codified abduction and present coherent interpretations of what has been revealed in the field. Given this, when we establish the Strategic Questions discussed in this study based on the narrative data, this conclusive path is derived from the researcher's exercising of a hypo-codified abduction movement. 
(3) Meta-abduction: finally, after these two abductive movements, the third movement has to do with meta-abduction, which "Consists of deciding if the possible universe delineated by our first level abductions is the same universe as our experience. In the hyper- and hypocodified abductions, this metalevel of inference is indispensable, given that we extract the law [or scientific-theoretical explanation of this study] from the baggage of the experience of effectively controlled worlds [here of already presented scientific theories and evidence]" (Eco, 2015, p. 203). Thus, based on the disconnected narrative evidence subjected to codification, aligned to follow a coherent order, we are finally able to establish a theoretically based meta-abductive inference that enables us to draw conclusions and extrapolate to analytical theoretical contributions, making it possible to establish explanations that weave together the theoretical approaches delineated in this study.

These three types comprise and constitute the first phase of this study, creating the conditions that provide the second part with context and plausibility in terms of analysis. We used the suggestions of Latour (2005), initiating an open analysis that seeks to explore the heterogeneity and multiplicity of the participants. In other words, once we have clarity in terms of the phenomenon under examination, we can point out the actors identified in the data, including humans or artifacts (non-humans) that act or are put into action in the course of organizational activities.

Next, we explore the interactions between the (previously identified) actors to understand how their relationships form or construct a "relationship network." Finally, we seek to describe how a group of actors, acting together, has come to have a unique voice (in other words, has become a notable actor). Since the analytical approach is relational, the focus of analysis is on what happens between the actors, that is, how they change by interacting with each other. In other words, instead of examining what has happened cognitively or behaviorally at the actor level (typically involving a human being or a group of human beings), we sought to understand what has happened "relationally," that is, understanding how multiple actors (human and non-human) are connected, and how they have changed through interactions, and how as a result these interactions constitute hybrids - such as indices, methodologies, and programs - that are also a part of and function within this network (Law, 1999).

The second phase, based on the discovered relationships, is to develop a narrative description of the three strategic questions ${ }^{3}$ (which are detailed in the following section). These three strategic questions constitute objects of the relationships that have been constructed over time and, as a result, they have emerged as units of meaning to the researchers organizing the data collected in the search for explanations, as detailed by Langley (1999). Based on these strategic narratives, we examined the relationship between the empirical material and the theoretical approaches of open strategy and translation. In this second phase, we maintained the abductive logic of investigation, which made it possible to reveal new dimensions and the theoretical nuances of the phenomenon in question, based on the actors, networks, and relationships identified in the first phase.

For the two phases described, we opted to use narratives as a way to analyze and present the data. This assumes the narrative nature of human existence and the need for subjects to structure the meaning of what they do through these narratives (Fisher, 1984). Thus, narrative analysis makes it possible to understand and organize data based on the sequence/patterns of events, focal actors, their roles, social and demographic networks, the voice, point of view, social relationships, and the power involved; the moral context, along with the values and assumptions that sustain them; and other indicators which are capable of signifying the subject and its relationships (Pentland, 1999). To present this data, the use of narratives allows the researcher to establish a nexus and chronological order for the data, telling the story of the research, 
which makes it possible to give a confusing and unordered mass of data produced by the collection process form and meaning in presenting our findings (Czarniawska, 1998).

\section{Results analysis and interpretation}

This section consists of (i) a description of the results using an organizational narrative that revolves around three strategic questions, and (ii) an analysis of the results, which present open strategy as a response to hybridism and the translation process to sustain this openness.

\section{I The construction of an organizational narrative}

This case study is told chronologically in terms of the strategic process that involved the formation and expansion of the portfolio of services offered by the organization under examination. The process has been separated to present the research results as narratives relating to three strategic questions. These narratives make it possible to understand the paths the organization has covered, and they are the basis for the interpretation of the practices of open strategy and the translation process, which will be elaborated in the following subsections.

The "Once upon a time" of this organization begins with the dilemma regarding the definition of the organization's purpose: the founders did not know which way they wanted to help institutions that assist handicapped individuals, even though there was certainty in terms of the social cause that they wished to further. Within the business structuring process, they created various programs, methodologies, and tools, which we will present through these three strategic questions.

Strategic Question 1: Creation of a Development Index for Handicapped People (IDEE)

Given the initial dilemma presented above, it is necessary to point out that the central characters in this story - the founders -created and developed their first ties in business school.
While students, they began hatching this idea of a social cause, and once they graduated, they began to articulate their entire business idea based on their knowledge of administration and economics. Thus, the path to beginning to structure "how" to further their social cause as a business began with the organization's creation of a development index for handicapped people (IDEE). "We needed a tool to understand institutions better" (Subject 1 - Executive Director), and so the process of creating/structuring this index was carried out through multiple interactions over time. These interactions involved internal as well as external actors.

However, the creation of the tool was not only motivated by the need to map the situation at institutions. The index also met a demand from institutions that did not have a good idea of their own situation, as well as from investing organizations (financers) that required evidence that ES's work was professional and efficient. The decision to create the index to understand the situation of these institutions was the result of a series of interactions between ES and other actors, such as the board members, investing organizations, and institutions. In other words, there was no single and conscious decision to create the IDEE (in the form that it is used by the organization today), but rather it involved a continual process of structuring this tool to accommodate the relationships with various actors within the network.

At this moment in the story, the creation of the IDEE began to provide clarity to the founders, partners (financers), and institutions affected by ES's business. But the founders began to perceive that the question of showing exactly how they could have an impact was essential to the scalability of the business. There would be no sustaining the constructed relationships if the results were not clear and transparent: providing available numbers and information, and the latent tension with the investing organizations in terms of the results of the investments made, motivated the creation of a document called the 'Impact 
Report.' This report consists of an annual printed publication that presents the main results achieved during the period.

Analyzing it from a time perspective, going from the application of a small script full of questions in 2009 to understand a given organization, to the creation of an annual index based on 120 indicators in 2011, and the preparation of the first impact report in 2013 , there was a series of interactions that sought to strengthen, improve, and stabilize the relationships between ES and the other actors that it interacted with. The use of tools to measure the relationships between these actors at times drove the actions of ES. Through a longitudinal approximation that the narratives make possible (Czarniawska, 1998), we can understand that strategic decisions have been motivated by the creation, strengthening, and maintenance of the ties between actors and the actor network and have counted on the participation of multiple actors within the enterprise's network.

Strategic Question 2: Acting through Organizational Volunteer Work

Beyond the initial challenge of sustaining the business idea, as narrated above, another fundamental strategic question in the formation of ES's service portfolio centered on resources to make the business viable and sustain the cause. Initially the financial support that ES received from partner organizations was accomplished through social donations of grants. Or in other words, an organization would provide financial support to the projects that ES developed in exchange for the potential development of the teaching institutions for handicapped individuals. However, since this investment was primarily social, without a direct return for the supporting organization, there was little motivation for this type of investment by investing organizations. The abstract nature of these returns was undermining the relationship network that sustained the organization. In 2010, for example, the members of ES held more than fifty-six meetings with various potential partners in search of investments, but only one made a social donation. One of the actors recognizes that in the beginning, "In terms of returns, we didn't know how to position ourselves" (Subject 3 -Commercial Director). But, this story began to change at the end of 2010: "we began to hear something about volunteer work, in the sense that volunteer work offers companies a return, because it is a way to motivate their employees, a way for team members to get to know each other better, and a way for teams to integrate" (Subject 1 Executive Director). At this point, the founders perceived that returns in terms of corporate volunteer work could provide relevant material stability for the relationship networks that began to form to sustain the business: thus, ES began to organize volunteer activities in the affected organizations for employees of the sponsoring organizations (partners). These volunteers were ready to help with renovating and painting the institutions and also gave classes on managementrelated subjects to institution directors.

Direct actions of the affected organizations involving corporate volunteer work represent a more attractive return for an investing organization. In addition to the social impact generated by the institution that takes care of handicapped individuals, these actions promote a positive image of the investing organization in the community, in the media, and among the participating employees themselves. These interactions involving employee volunteers in environments outside of the organization promote greater integration among the employees, which can improve the organizational environment. Volunteer work as a return, which was instituted in 2011, is a strategic question that has positively affected the investing organizations, because they have come to involve their internal stakeholders in these actions, and it has also affected ES, which has significantly increased the financial support it receives. Finally, the initiative benefits the institutions, which now receive, along with projects and diagnoses directly carried out by ES, volunteer work to improve their physical structure and training of their directors and employees. 
In 2014, however, it was perceived that some of the organizations were having difficulty fielding enough volunteers to meet the demands of the affected organizations, which compromised the results of the volunteer programs organized by ES.

Given this scenario, through the internal mediation of ES employees and interaction with the financing organizations themselves, the corporate volunteer work management methodology was created. The proposal was to no longer carry out volunteer work alone and begin to work on continuous programs of awareness, mobilization, and recognition of the employees of partner organizations who do volunteer work to help handicapped individuals. In other words, ES began to act as a "consultant" to the organizations to help manage corporate volunteer work. This process led to a change in the way ES interacts with the partner organizations, given that organizations no longer "buy" volunteer work and have begun to count on continuous work by ES, involving, in general, greater closeness and interaction between the human resources and communications departments in the partner organizations.

In this movement, the 'Teach' program was also created, in which the volunteer works with a handicapped person directly. In the previous programs, the volunteers only had contact with the school's directors and/or physical structure, given that the renovations took place on days when the schools were not in session. To bring the volunteer closer to the handicapped individuals, the program seeks to raise awareness to attract volunteers to the cause and thus maintain volunteer "loyalty."

In addition, a program called 'Special Leader' was developed, which fosters the development of a set of leadership qualities through direct interaction with the institution directors. It focuses on the development of skills in a more explicit manner, because the volunteer activities are performed directly with the directors of the affected organizations and are thought out as a group, analyzing the organization's needs and the skills that the volunteer needs to develop. This program includes volunteers from middle to top management, promoting the development of managerial corps in the schools through excellence programs specially designed for their needs, and this makes it possible for ES to commercialize this program as training instead of social investment. This commercial change, especially for large partner organizations, represents a way to increase ES's financial returns, given that the budget for training in these organizations is greater than the budget for social investment.

In terms of Strategic Question 2, the strategic process of creating/developing new programs, volunteer methodologies, and changes in interactions with investing organizations, makes it possible to analyze whether the entire strategic process is run continually to establish and strengthen actor-networks.

Strategic Question 3: Continuous Activities Together with the Institutions (ES Network)

ES acts through the application of the annual diagnostic (IDEE), continually develops projects to improve management, and also organizes corporate volunteer work. Yet, as a result of ES's own actions, there was an increase in the number of schools involved. In 2014, for example, there were more than 60 institutions where this work took place.

With the expansion of the number of institutions, those which had been working for ES for longer, and had already benefited from projects and/or volunteer work, now felt that they were more distant from ES due to their interactions not being as intense or frequent as they used to be. In other words, ES connected with the affected institution for only part of the year to research the information needed to prepare the diagnostic and present its results.

As a way to revert this weakening of its relationships, ES has developed the "ES Network," to create closer ties between the affected institutions and ES itself. Its first initiative 
was to create the "Good Practices Breakfast", in which one morning a month all of the institutions that work with ES get together to discuss a subject of common interest. The event is organized by ES, and features a guest speaker who makes and also presents a case study of some positive change carried out by one of the institutions.

Through this monthly interaction with these institutions via the Good Practices Breakfast, ES also promotes connections through the creation of an online group in an instant message app. It can be observed that this movement, carried out in an active manner by ES employees, involves decisions such as the creation of events, the integrated actions of these institutions, and using instant communication tools in order to strengthen their relationships. The result of this interaction has generated other activities for the ES portfolio such as the "Good Practices Guide," which is a printed report of successful practices implemented in various areas of management, and "IDEE Highlights," which is an annual event in which ES awards the institutions that have progressed the most.

Even though the three strategic questions have been presented in a separate manner, these strategic actions and decisions have been interwoven over time in the constant search to involve network actors, as we will see in the following analysis.

\subsection{Data analysis: open strategy as a response to hybridism and using the translation process to sustain this openness}

the described narratives confirm the three fundamental strategic questions of the ES organization. It can be observed that in the narratives presented the three strategic questions the creation of the IDEE, the volunteer program, and the establishment of networks - all arose as responses to sustain the relationship network that was necessary for the survival and development of ES as a social business. Thus, in accordance with Latour $(1987,2005)$ and Callon $(1986,1998)$, it can be observed that organizational existence cannot be understood based on an idea of identity, but rather as an interwoven material relationship network, given that the relationships between the network actors were constructed (or materialized) in time and space through the creation of indices, methodologies, meetings, reports, and awards.

The evidence of this process can be observed in the narrative descriptions employed. However, the central question of this study still needs to be confirmed. From the described narrative it can be perceived that the fundamental dilemma during all of the organization's operations (and which culminates in these three strategic questions) refers to the need to establish and sustain itself as a business, and at the same time, succeed in furthering its social cause. This fundamental tension created the need to first position itself as a business and secure sufficient financing to further its cause, and thus the IDEE appeared as a structuring artifact in the relationships established with the financers. Even though this artifact was relevant, the financers felt the need to materialize their investments, to see returns beyond the indicators, and thus the volunteer program came to sustain the relationship with the financers as a justification of their own business. At a third point in time, we can observe that the network between the affected organizations arose as a need to refocus on the cause, seeking to balance all the actions designed to sustain the business's focus up to that point. All of this represents a movement searching for a balance between the logic of the cause and the business, which indicates that the hybridism that results from the existence of conflicting forms of logic has required the elaboration of these specific organizational practices over the entire history of ES.

From the point of view of the open strategy, this balancing movement between the logic of the cause and the business also appears in the articulation between the various stakeholders that becomes evident in this process. ES has established itself as a "juggler" between these two tensions, exactly balancing in each hand the 
interests of the various involved parties. The open strategy perspective makes this possible through the processes that describe it, understood to be the strategic articulation of these various interests, as described below:

Inclusion. The practices of participative (re)definition and discussion of the strategic movements sustain the inclusion of stakeholders in the strategic process. With the inclusion of the various parties, the organizational limits become blurred. The members of the network feel free to contribute their ideas to the strategic process. In this inclusion process, it can be observed that emotional conflicts are reduced. Inclusion contemplates the involvement of other actors and the ability to relate with these actors in a constructive manner (Hautz et al., 2017).

Transparency. The continuous interaction process and the constant alignment between those involved underline the transparency of the strategic process. In this case, transparency goes beyond the communication of strategic decisions envisioned in the literature (Whittington et al., 2011) because there is a constant exchange of information about strategic questions with 'others' (individuals or organizations). With the alignment of interests and expectations in an incessant communications process, this also encourages the participation of network members in the strategic process, reducing conflicting objectives and static in terms of communications.

Flexibility. The customization practices for services and programs in accordance with the needs of partners and institutions, and constructive thinking in which ideas are incorporated in the strategic process, sustain the flexibility category. This category is related to the awareness that the organization's reality has changed, and therefore the organization needs to develop the ability to continually reorganize itself in light of these changes, taking advantage of stakeholder contributions. Flexibility avoids circular strategic processes, in which decisions are never made (Denis, Dompierre, Langley, \& Rouleau, 2011). Horizontalization. In terms of the horizontalization category, practices have been identified in terms of relationships without hierarchical differentiation and employing tools and methodologies that measure horizontal relationships with stakeholders. The use of instant electronic messaging groups promotes a perception of equality among all the participants, independent of hierarchical and relationship network positions. Horizontality goes beyond the hierarchical or organizational chart, transforming the mentality of those involved in thinking and acting with each other within a strategic process.

After understanding these different mechanisms in the strategic process, the relationship level at which this opening process should be articulated remains to be discussed. First it was perceived that there needed to be awareness, due to the hybrid nature of the business, with the stakeholders needing to understand and adhere to the social cause on which they were working. There was no protagonist beforehand, as there is in the questioning step (Callon, 1986). In this case, the business's social objective promotes a common form of passage for all involved. In terms of increasing awareness, the enterprise's role as a protagonist is achieved through its social objective. In other words, the credibility of the enterprise is promoted through printed material, awards, and videos designed to make potential network members aware of the cause in question. In this case, the identification of roles instead of their being imposed by power relationships is encouraged through continuous horizontal relationships and interactions between the members of the relationship network.

For the second moment in the translation process, it can be observed that, instead of the logic of interessement (Callon, 1986), there is an alignment of interests, expectations, and objectives between the parties. In other words, instead of imposing identities and roles and testing them, the network members are included through a discussion of movements, anticipated alignments among the parties, and constructivethinking routines.

The third moment is called engagement, and is sustained by the practices of customization and participative (re)definition. In this case, the acceptance of roles is constructed in such a way 
that those involved engage socially and financially in the projects that ES develops. The opening of the strategic process transforms the imposed process of enrollment (Callon, 1986) into a process of engagement in which the parties are conscious of their roles in the relationship network and begin to actively benefit it.

Finally, the fourth moment of agreement is supported by employing communication tools, which sustain the relationships between the network members. This moment differs from the moment of mobilization described by Callon (1986), because it does not distinguish a single 'spokesperson'. Through agreement, all of those involved become spokespeople for the social cause in question.

It can be perceived, in light of this, that the opening up of organizational strategy, which arises as a response to the context of the organizational hybridism that characterizes ES, is only sustained to the extent that it understands the process of translation, through which negotiation occurs until agreement is achieved - among the various stakeholders -to speak and act in the name of all in terms of this social cause. This process, as can be perceived by this description and data analysis, is not simple or passive and occurs over the course of its construction.

\section{Final considerations}

This study sought to analyze the organizational mechanisms adopted by a social enterprise to deal with the tensions that result from organizational hybridism. The case in point enabled us to carry out a deep longitudinal approximation of the movement of these relationships due to this strategic process.

It can be observed that a social enterprise involves various strategic practices that sustain inclusion, transparency, flexibility, and horizontalization as characteristics of an open strategy. Horizontalization of organizational relationships and flexibility of the strategic process are new categories that emerged in this study, and they have not been detailed in the open strategy literature. These new categories can complement the transparency and inclusion processes of the strategic process, thus avoiding closure of the process due to the inability of an organization to deal with the changes that result from the opening up of the process (Dobusch \& Müller-Seitz, 2014). It should be emphasized that the practices studied can be understood as a strategic response to the tensions of hybrid organizations.

In terms of the translation process, it can be observed that due to the multifaceted nature of the business (Batillana \& Lee, 2014), and therefore the political process of translation using the terms developed by Callon (1986), the relationships do not fit the reality under examination. It is believed that the imposition of identities and roles in the translation process (Callon, 1986) increases conflict, contradictions, and contestations among the members of the relationship network (Doherty et al., 2014). Thus, the practices of open strategy sustain a translation process that is appropriate for the hybrid characteristics of social enterprises, which occurs at four moments: (i) awareness; (ii) alignment; (iii) engagement; and (iv) agreement.

The use of actor network theory contributed to this study, specifically in terms of using the translation perspective to study social enterprises. The literature in this area has focused on discussing the phenomenon based on institutional, identity, organizational, stakeholder, and paradox theory (Smith et al., 2013). Because it encourages a relational and diffuse look at interactions, actor-network theory can offer new insights to this area of study. In terms of the open strategy process (Whittington et al., 2011), as well as the inclusion and transparency dimensions indicated in the literature (Hautz et al., 2017), the flexibility and the horizontalization process of the relationships appear as new dimensions of the phenomenon under study. This study also contributes to rethinking the translation process presented by Callon (1986) in relation to hybrid organizations, suggesting moments less centered on the political imposition of roles and identities. The social objective of the enterprise under study alters the form of the strategic practices and the translation process of the relationship networks. 
It should be noted, however, that this study has some relevant limitations. First of all, despite the justification for a single case, the organization studied is not a typical model for most Brazilian social enterprises. Its founding partners have a solid background in management and have a command of business logic; on the other hand, studies (e.g. Salvador \& Rese, 2017) show that many social enterprises begin with a focus on the cause and go through crises, which can even be fatal, when the logic of business imposes itself. This entire context means that this study cannot be the basis for typical analytical generalizations to social enterprises, even though it sheds light on organizing in a relevant social enterprise such as ES. However, even though it is recognized by the relational ontology adopted in this study that this reality cannot be understood in isolation from these interwoven relationships, the extent to which the researcher becomes immersed in the research context and becomes an actor in the network can be pointed out as a second limitation, with an interpretive bias, given that it is accepted that "every interpreter of a text realizes abductions to choose between many possible readings of the text" (Eco, 2015, p. 208). Thus, despite all the methodological care that was taken in this study, we cannot omit the question of interpretation.

Given these aspects, it is understood that future research could address typical social enterprises, seeking to understand how the conflicting forms of logic can lead to lowerthan-expected performance or limitations to achieving results due to their causes. Nonetheless, investigating the relationship between the degree of hybridism and the degree of open strategy in various organizations appears to be another fruitful path of research. It can be perceived, in addition to these questions, that another interesting relationship to be investigated has to do with the context of mediazation (Couldry $\&$ Hepp, 2017), in which relationships are more and more interwoven in the engagement of human and non-human actors in a horizontal manner. Investigating the phenomenon of opening strategy in these contexts of social hyper-exposure and relationships that are less and less centered on face-to-face interaction appears to be fundamental as well. Another aspect that seems interesting in terms of this mediazation rationale is the fact that more and more organizations are subject to social judgements, in that relationships are no longer confined to the production context, and results are exposed, judged, and endorsed (or not) by a society that attentively follows them through social networks (for example). Could it be that we are at an inflection point, in the sense that ever more enterprises will have to worry about social impacts related to a "cause" in addition to the traditional generation of profit? Could it be that social enterprises will continue to be different types of business, or given the degrees of hybridism, will traditional organizations tend to move closer to this type of business model? These are questions - some narrower, some broader that result from the abductive analysis process adopted in this paper.

\section{References}

Battilana, J., \& Dorado, S. (2010). Building sustainable hybrid organizations: The case of commercial microfinance organizations. Academy of Management Journal, 53(6), 1419-1440.

Battilana, J., \& Lee, M. (2014). Advancing research on hybrid organizing-Insights from the study of social enterprises. The Academy of Management Annals, 8(1), 397-441.

Battilana, J., M. L. Besharov, \& B. C. Mitzinneck (2017). On hybrids and hybrid organizing: A review and roadmap for future research. In $\mathrm{R}$. Greenwood, C. Oliver, R. Suddaby, and K. Sahlin-Andersson (eds.), The Sage Handbook of Organizational Institutionalism: 132-169. Thousand Oaks, CA: Sage.

Besharov, M. L., \& Smith, W. K. (2014). Multiple institutional logics in organizations: Explaining their varied nature and implications. Academy of Management Review, 39(3), 364-381.

Billis, D. (2010). Hybrid organizations and the third sector: Challenges for practice, theory and policy. Basingstoke: Palgrave Macmillan. 
Bridgstock, R., Lettice, F., Özbilgin, M. F., \& Tatli, A. (2010). Diversity management for innovation in social enterprises in the UK. Entrepreneurship and Regional Development, 22(6), 557-574.

Callon, M. (1980). Struggles and Negotiations to Define what is Problematic and what is not: The Socio-logics of Translation'. In: K. Knorr, R. Krohn \& R. Whitley (eds.), The Social Process of Scientific Investigation. pp. 197-219. Dordecht: D. Reidel Publishing Co.

Callon, M. (1986). Some elements of a sociology of translation: domestication of the scallops and the fishermen of St Brieuc Bay. The Sociological Review, 32(S1), 196-233.

Callon, M. (1998). An essay on framing and overflowing: economic externalities revisited by sociology. The Sociological Review, 46(S1), 244-269.

Camillis, P. K. D., Bussular, C. Z., \& Antonello, C. S. (2016). A agência a partir da Teoria AtorRede: reflexôes e contribuiçôes para as pesquisas em administração. Organizaçóeser Sociedade, 23(76), 73-91.

Couldry, N., \& Hepp, A. (2017). The Mediated Construction of Reality. London: Polity.

Czarniawska, B. A. (1998). A narrative approach to organization studies. London: Sage Publications.

Dacin, M. T., Dacin, P. A., \& Tracey, P. (2011). Social entrepreneurship: A critique and future directions. Organization science, 22(5), 12031213.

Denis, J. L., Dompierre, G., Langley, A., \& Rouleau, L. (2011). Escalating indecision: Between reification and strategic ambiguity. Organization Science, 22(1), 225-244.

Dobusch, L., Seidl, D., \& Werle, F., (2014). Opening up the strategy-making process: comparing open strategy and open innovation. Working Paper, Abstract published in Academy of Management Proceedings.

Doherty, B., Haugh, H., \& Lyon, F. (2014). Social enterprises as hybrid organizations: A review and research agenda. International Journal of Management Reviews, 16(4), 417-436.

Eco, U. (2015). Os limites da interpretação. São Paulo: Perspectiva.

Fisher, W. R. (1984). Narration as a human communication paradigm: the case of public moral argument. Communication Monographs, 51(1), 1-22.

Friedland, R., \& Alford, R. R. (1991). Bringing society back in: Symbols, practices and institutional contradictions. In W. W. Powell \& P. J. DiMaggio (Eds.), The new institutionalism in organizational analysis: 232-267. Chicago: University of Chicago Press

Ghemawat, P. (2002). Competition and business strategy in historical perspective. Business History Review, 76(01), 37-74.

Guimarães, P. C. V., \& Alves, M. A. (2014). Narratives and sensemaking of an organizationallybased environmental disaster. Brazilian Administration Review - BAR, 11(2), 228-247.

Hambrick, D. C., Finkelstein, S., \& Canella Jr., A. A. (2009). Strategic Leadership: theory and research on executives, top management teams, and boards. Oxford University Press.

Hautz, J., Seidl, D, \& Whittington, R. (2017). Open strategy: dimensions, dilemmas, dynamics. Long Range Planning, 50(3): 298-309.

Hoffman, A., Badiane, K., \& Haigh, N. (2012). Hybrid organizations as agents of positive social change: Bridging the for-profit \& non-profit divide. In K. Golden-Biddle \& J. Dutton (Eds.). Using a positive lens to explore social change and organizations: Building a theoretical and research foundation (pp. 131-150). New York: Routledge.

Langley, A. (1999). Strategies for theorizing from process data. Academy of Management Review, 24(4), 691-710.

Latour, B. (1987). Science in Action - How to Follow Scientists and Engineers Through Society, Harvard University Press, Cambridge, MA. 
Latour, B. (2005). Reassembling the social: An introduction to actor-network-theory. Oxford University Press.

Mantere, S., \& Vaara, E. (2008). On the problem of participation in strategy: A critical discursive perspective. Organization Science, 19(2), 341-358.

Mintzberg, H. (1987). The strategy concept: five p's for strategy. U. of California.

Ocasio, W, Thornton, P. H., \& Lounsbury, M. (2017). The institutional logics perspective. In R. Greenwood, C. Oliver, R. Suddaby, and K. Sahlin-Andersson (eds.), The Sage Handbook of Organizational Institutionalism: 132-169. Thousand Oaks, CA: Sage.

Pentland, B. T. (1999). Building process theory from narrative: from description to explanation. Academy of management review, 24(4), 711-724.

Rese, N., Salvador, D. W., \& Araújo, L. G. (2016). "Jogo" ou "Blefe": uma Discussão sobre as Respostas Estratégicas diante da Complexidade Organizacional. Encontro Nacional da Associação Nacional Pós-Graduação em Administração. Anais... Rio de Janeiro, ANPAD.

Salvador, D. W., \& Rese, N. (2017). O Sensegiving no Processo de Elaboração de Sentido da Estratégia em Pequenas Empresas Caracterizadas como Organizações Híbridas. REGEPE, 6(1), p. 128-159.

Smith, W. K., Gonin, M., \& Besharov, M. L. (2013). Managing social-business tensions: A review and research agenda for social enterprise. Business Ethics Quarterly, 23(03), 407-442.

Stake, R. (2000). The case study method in social inquiry. In Norman K. Denzin \& Yvona Lincoln S. The American tradition in qualitative research. Vol. II. Thousand Oaks, California: Sage Publications.

Tureta, C., \& Lima, J. B. de. (2011). Estratégia como prática social: o estrategizar de uma rede interorganizacional. RAM-Revista de
Administração Mackenzie, 12(6), 76-108.

Tureta, C., Tonelli, M. J., Alcadipani, R. (2011). O gerente-ciborgue: metáforas do gestor "póshumano. Organizaçôes ঔ́Sociedade, 18(58), 467486.

Vaara, E., Sonenshein, S., \& Boje, D. (2016). Narratives as Sources of Stability and Change in Organizations: Approaches and Directions for Future Research. The Academy of Management Annals, v. 10, n. 1, p. 495-560.

Vaara, E. \& Whittington, R. (2012). Strategyas-practice: taking social practices seriously. The Academy of Management Annals, 6(1), 285-336.

Wæraas, A., \& Nielsen, J. A. (2016). Translation theory 'translated': Three perspectives on translation in organizational research. International Journal of Management Reviews, 18 (3), 236-270.

Whittington, R., Cailluet, L., \& Yakis-Douglas, B. (2011). Opening strategy: Evolution of a precarious profession. British Journal of Management, 22(3), 531-544.

Whittington, R., Hautz, J., \& Seidl, D. (2014). Open Strategy: transparency and inclusion in strategy processes. Long Range Planning, Vol. 50, No. 1, pp.1-4.

\section{Notes}

1 Organizing refers to a renunciation of the understanding that the activity of organizing is static and focused on entities, but is instead a constant movement that is appropriate for each organization's situation.

2 The terms framing, interessement, and enrollment are explained in greater detail by Callon (1986).

3 The strategic questions in this paper refer to subjects that were the object of decisions made by the strategic corps of the organization researched around which the investigated relationships were established. In light of the narrative employed in this paper, strategic questions figure as the thematic narratives of the actors involved in these relationships. 


\section{Supporting Agencies:}

This study was financed in part by the Coordenação de Aperfeiçoamento de Pessoal de Nível Superior Brazil (CAPES) - Finance Code 001 and by CNPq, Conselho Nacional de Desenvolvimento Científico e Tecnológico - Brazil.

\section{Authors:}

1. Eduardo Guedes Villar, PhD in Business Management, Federal University of Paraná.

E-mail: eduardogvillar@gmail.com

ORCID

(iD) 0000-0001-5005-4099

2. Natália Rese, PhD in Business Management, Federal University of Paraná.

E-mail: resenati@gmail.com

\section{ORCID}

(iD) 0000-0003-2043-3092

3. Karina De Déa Roglio, PhD in Production Engineering, Federal University of Santa Catarina. Email: karinaroglio@gmail.com

ORCID

(iD 0000-0002-5256-8330

\section{Contribution of each author}

\begin{tabular}{|c|c|c|c|}
\hline Contribution & Eduardo Villar & Natalia Rese & Karina Roglio \\
\hline 1. Definition of research problem & $\sqrt{ }$ & $\sqrt{ }$ & $\sqrt{ }$ \\
\hline 2. Development of hypotheses or research questions (empirical studies) & $\sqrt{ }$ & $\sqrt{ }$ & $\sqrt{ }$ \\
\hline 3. Development of theoretical propositions (theoretical work ) & $\sqrt{ }$ & $\sqrt{ }$ & $\sqrt{ }$ \\
\hline 4. Theoretical foundation/ Literature review & $\sqrt{ }$ & $\sqrt{ }$ & \\
\hline 5. Definition of methodological procedures & $\sqrt{ }$ & & $\sqrt{ }$ \\
\hline 6. Data collection & $\sqrt{ }$ & & \\
\hline \multicolumn{4}{|l|}{ 7. Statistical analysis } \\
\hline 8. Analysis and interpretation of data & $\sqrt{ }$ & & \\
\hline 9. Critical revision of the manuscript & & $\sqrt{ }$ & $\sqrt{ }$ \\
\hline 10. Manuscript writing & $\sqrt{ }$ & $\sqrt{ }$ & \\
\hline 11. Other (please specify which) & & & \\
\hline
\end{tabular}

